\title{
Improving activity and enantioselectivity of lipase via immobilization on macroporous resin for resolution of racemic 1- phenylethanol in non-aqueous medium
}

\author{
Xiang Li, Shuangshuang Huang, Li Xu and Yunjun Yan ${ }^{*}$
}

\begin{abstract}
Background: Burkholderia cepacia lipase $(\mathrm{BCL})$ has been proved to be capable of resolution reactions. However, its free form usually exhibits low stability, bad resistance and no reusability, which restrict its further industrial applications. Therefore, it is of great importance to improve the catalytic performance of free lipase in non-aqueous medium.

Results: In this work, macroporous resin NKA (MPR-NKA) was utilized as support for lipase immobilization. Racemic transesterification of 1-phenylethanol with vinyl acetate was chosen as model reaction. Compared with its free form, the enzyme activity and enantioselectivity (ee $)$ of the immobilized lipase have been significantly enhanced. The immobilized $\mathrm{BCL}$ exhibited a satisfactory thermostability over a wide range of temperature (from 10 to $65^{\circ} \mathrm{C}$ ) and an excellent catalytic efficiency. After being used for more than 30 successive batches, the immobilized lipase still kept most of its activity. In comparison with other immobilized lipases, the immobilized BCL also exhibits better catalytic efficiency, which indicates a significant potential in industrial applications.

Conclusion: The results of this study have proved that MPR-NKA was an excellent support for immobilization of lipase via the methods of $\mathrm{N}_{2}$ adsorption-desorption, scanning electron microscopy (SEM), energy dispersive spectroscopy (EDS) and Fourier transform-infrared spectroscopy (FT-IR). The improvement of enzyme activity and $e_{\mathrm{s}}$ for the immobilized lipase was closely correlated with the alteration of its secondary structure. This information may contribute to a better understanding of the mechanism of immobilization and enzymatic biotransformation in non-aqueous medium.
\end{abstract}

\section{Background}

In recent years, lipase (EC 3.1.1.3) has been widely applied in biotransformation reactions in aqueous and non-aqueous medium, because it can be used to catalyze hydrolysis and transesterification reactions, as well as synthesis of esters [1]. Especially, the ability of lipases to perform enantioselective biotransformation in preparation of pharmaceutical intermediates and chiral building blocks has made them increasingly attractive and promising [2]. Particular attention has been paid to the Burkholderia cepacia strain, which can produce versatile

\footnotetext{
* Correspondence: yanyunjun@hust.edu.cn

Key Laboratory of Molecular Biophysics of the Ministry of Education, College of Life Science and Technology, Huazhong University of Science and Technology, Wuhan 430074, China
}

(c) 2013 Li et al.; licensee BioMed Central Ltd. This is an open access article distributed under the terms of the Creative Commons Attribution License (http://creativecommons.org/licenses/by/2.0), which permits unrestricted use, distribution, and reproduction in any medium, provided the original work is properly cited. enzyme and be widely used for biodegradation, biological control and hydrolyzing biotransformation in various reactions [3]. The lipase from Burkholderia cepacia lipase (BCL) has high stability, alcohol tolerance and activity suitable for a broad spectrum of reactions substrates and media [4]. However, its free form usually exhibits low stability, bad resistance and no reusability, which restrict its further application in industry [5]. In most cases, these disadvantages of directly using free form lipase are common phenomena in other enzymecatalyzed reactions [6,7]. Thus, the issue focusing on how to improve the catalytic properties of free lipase (such as activity, thermal stability and reusability) in non-aqueous medium is an important topic.
C Biomed Central 
Immobilization has been proved to be one of the most useful strategies to improve catalytic properties of free enzyme [8]. There are several conventional immobilization approaches, such as adsorption, entrapment, encapsulation, and covalent binding $[9,10]$. Among them, adsorption is advantageous because of its procedural simplicity, low cost, high efficiency and ease of industrial application. Immobilized lipases via adsorption methods have been used in many reactions, such as ester synthesis, biodiesel production and enrichment of polyunsaturated fatty acids $[5,11,12]$. So far, various materials have been employed as supports for enzyme immobilization [13]. However, usage of MPRs in the resolution reaction has rarely been explored. Although many studies showed that immobilization could greatly enhance the catalytic performance of enzyme [14,15], till now, to the best of our knowledge, it is still unclear that why immobilization can enhance the activity and tolerance of lipases. Thus, it is important to elucidate the possible mechanism of this enhancement.

For this purpose, in this study, several methods $\left(\mathrm{N}_{2}\right.$ adsorption-desorption, SEM, EDS and FT-IR) were employed to characterize the immobilized lipase in order to investigate probable mechanism for the enhancements of enzyme activity and enantioselectivity after immobilization. The enantioselective transesterification of racemic 1-phenylethanol with vinyl acetate was chosen as the model reaction so as to evaluate the enzyme activity/enantioselectivity $\left(e e_{\mathrm{s}}\right)$ and to compare the catalytic efficiency between the free and immobilized lipases in non-aqueous medium [16], because secondary alcohols are often used as target substrates in lipase-catalyzed resolution reactions [17]. In addition, 1phenylethanol is an essential building block and synthetic intermediate in many fields, such as fragrance in cosmetic industry, solvatochromic dye in chemical industries, ophthalmic preservative and inhibitor of cholesterol intestinal adsorption in pharmaceutical industries [18]. Moreover, numerous reports on transesterification of racemic 1-phenylethanol with vinyl acetate are available in the literature, we can easily compare the catalytic activity of immobilized BCL with other enzyme catalysts under similar reaction conditions.

Therefore, based on the above analysis, the main objectives of this work are: (1) to compare the properties of the free lipase and the immobilized lipase on MPRs based on the reaction parameters, such as temperature, water content, substrate molar ratio, and reaction time; (2) to investigate probable mechanism for the significant improvement of enzyme activity and enantioselectivity through various characterizations of the immobilized lipase; and (3) further to compare the catalytic efficiency between the immobilized BCL and other immobilized lipases.

\section{Results and discussion MPR selection}

The enzyme activities and immobilization efficiencies of the 5 types of MPRs are presented in Figure 1. The properties of MPRs, such as particle size, specific surface area and pore diameter, were listed in Table 1.

As shown in Table 1, MPRs were synthesized from inexpensive styrene. Actually, they had relatively low price (\$5-12/kg). The result in Figure 1 showed that the enzyme activity and immobilization efficiency both were highest as compare with the other MPRs, when BCL was immobilized on MPR-NKA. The reason was mainly attributed to different specific surface area and pore diameter. Among these five types of MPRs, NKA had relatively higher specific surface area and average pore diameter (> $20 \mathrm{~nm}$ ). Gao et al. [12] has also made similar conclusion that pore diameter of resin influences immobilization degree where immobilization degree increased with the increment of pore diameter. Therefore, MPR-NKA was chosen as the immobilization matrix in the following experiments.

\section{Effect of substrate molar ratio on enzyme activity/ee $e_{s}$ of the free and immobilized $\mathrm{BCL}$}

As shown in Figure 2, the effect of substrate molar ratios of vinyl acetate to racemic 1-phenylethanol from 1:1 to 10:1 has been investigated. It is generally believed that the acyl donor concentration would affect the reaction equilibrium, because the excess amount of vinyl acetate could drive the reversible reaction to the right side. For the free lipase, it could be observed that the highest enzyme activity and $e e_{\mathrm{s}}$ was obtained when the substrate ratio was 4:1. However, it could also be found from Figure 2 that further increase of substrate ratio had little effect on the enzyme activity and enantioselectivity of the free and immobilized BCLs when the molar ratios were more than $4: 1$.

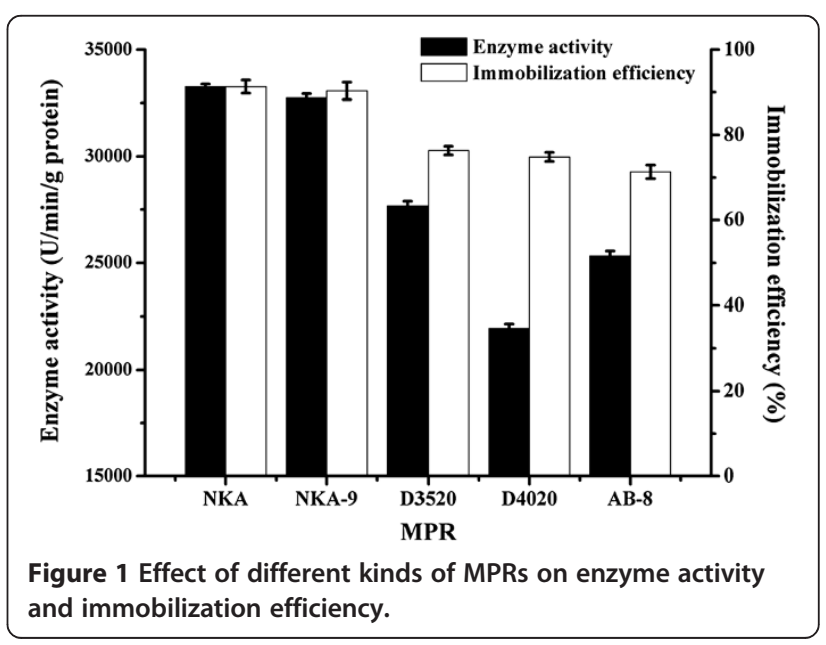


Table 1 Properties of MPRs used in the present study

\begin{tabular}{lcccccc}
\hline Items & Matrix structure & Density $(\mathbf{g} / \mathbf{m L})$ & Particle size $(\boldsymbol{\mu m})$ & Specific surface area $\left(\mathbf{m}^{\mathbf{2}} \mathbf{g}\right)$ & Porosity $(\%)$ & Average pore diameter $(\mathbf{n m})$ \\
\hline D3520 & Crosslinked Polystyrene & $1.02-1.06$ & $300-1250$ & $480-520$ & $65-70$ & $8.5-9.0$ \\
D4020 & Crosslinked Polystyrene & $1.08-1.12$ & $300-1250$ & $540-580$ & $46-50$ & $10-10.5$ \\
NKA & Crosslinked Polystyrene & $1.02-1.06$ & $300-500$ & $570-590$ & $78-80$ & $20-22.0$ \\
AB-8 & Crosslinked Polystyrene & $1.02-1.08$ & $480-520$ & $480-520$ & $42-46$ & $13-14.0$ \\
NKA-9 & Crosslinked Polystyrene & $1.02-1.04$ & $300-700$ & $540-580$ & $74-78$ & $15.5-16.5$ \\
\hline
\end{tabular}

Effect of water content on enzyme activity/ee ${ }_{s}$ of the free and immobilized BCL

When a reaction is performed in organic medium, the enzyme activity would be affected by micro-water in the reaction system [19]. In addition, water has different effects on the enzyme activity and enantioselectivity in various lipase-catalyzed reactions [20]. The influence of water on the BCL-catalyzed reaction was investigated in a range of water contents from $0.02 \mathrm{mmol} / \mathrm{mL}$ to $0.80 \mathrm{mmol} / \mathrm{mL}$. As can be seen in Figure 3, for the free lipase, the enzyme activity decreased significantly, while the $e e_{s}$ was observed to be correlated well with the decrease of enzyme activity. It indicates that high water content may lead to an increase in hydrolysis, resulting in the decrease in transesterification activity of the enzyme. For the immobilized lipase, the enzyme activity and $e e_{s}$ also showed a similar decrease in tendency, which can be explained as that extra water would accumulate inside the immobilized lipase and influence the flexibility of the protein [21]. Therefore, there is no necessity to add extra water during the reaction, as the immobilized lipase has contained necessary water to maintain its active conformation during immobilization process.

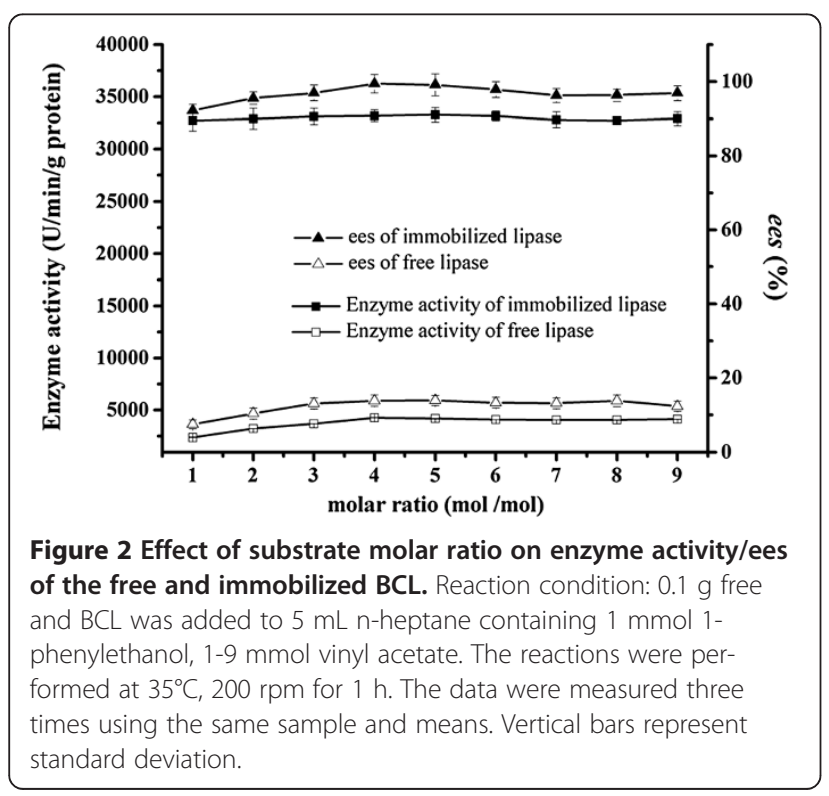

Effect of temperature on enzyme activity/ee $e_{s}$ of the free and immobilized BCL

The effect of temperature from 10 to $65^{\circ} \mathrm{C}$ on the enzyme activity and $e e_{s}$ of the free and immobilized BCL for resolution of $(R, S)$-1-phenylethanol was examined (Figure 4). For the free lipase, the enzyme activity increased with the increment of temperature when temperature was below $55^{\circ} \mathrm{C}$, which agrees with the observation of Phillips [22]. The $e e_{s}$ also grew with the increase of temperature. When the temperature was above $55^{\circ} \mathrm{C}$, both enzyme activity and $e e_{s}$ decreased, which indicates that higher temperature would inhibit enzyme activity. For the immobilized lipase, enzyme activity and $e e_{s}$ were a little lower when temperature was below $20^{\circ} \mathrm{C}$, which was attributed to heterogeneous mixture of substrate, acyl donor and organic medium at lower temperature. Compared with the free lipase, enzyme activity and $e e_{s}$ of the immobilized lipase exhibited no obvious decrease when temperature was over $20^{\circ} \mathrm{C}$, which suggested immobilization could improve the thermostability of lipase.

\section{Effect of reaction time on conversion/ee $e_{s}$ of the free and immobilized $\mathrm{BCL}$}

As shown in Figure 5, the conversion of the free lipase increased with the reaction time at a very slow rate, and

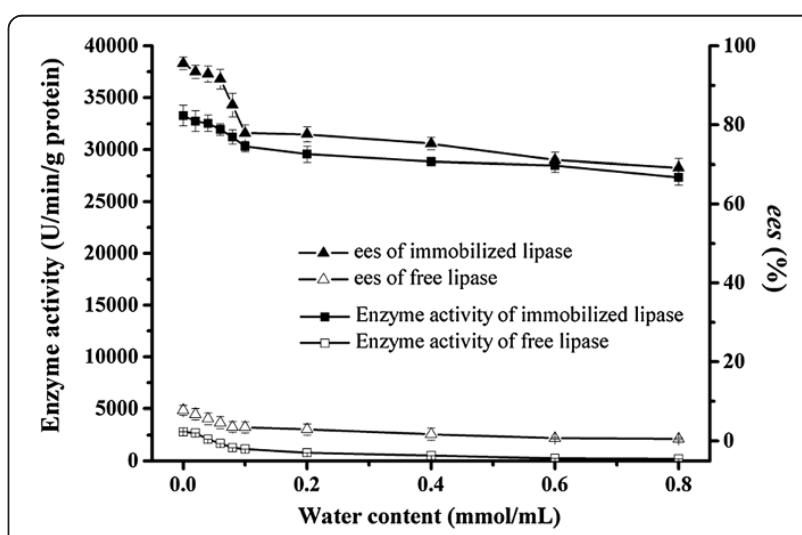

Figure 3 Effect of water content on enzyme activity/ees of the free and immobilized BCL. Reaction condition: $0.1 \mathrm{~g} \mathrm{BCL}$ was added to $5 \mathrm{~mL} \mathrm{n}$-heptane containing $1 \mathrm{mmol}$ 1-phenylethanol, 4 $\mathrm{mmol}$ vinyl acetate. The reactions were performed at $35^{\circ} \mathrm{C}, 200 \mathrm{rpm}$ for $1 \mathrm{~h}$. The data were measured three times using the same sample and means. Vertical bars represent standard deviation. 


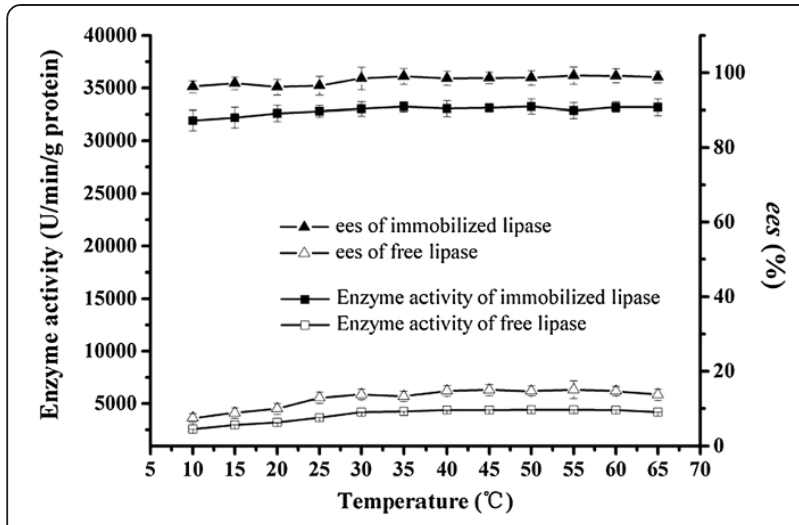

Figure 4 Effect of temperature on enzyme activity/ ees of the free and immobilized BCL. Reaction condition: $0.1 \mathrm{~g} \mathrm{BCL}$ was added to $5 \mathrm{~mL}$-heptane containing $1 \mathrm{mmol}$ 1-phenylethanol, 4 mmol vinyl acetate. The reactions were performed at different temperatures, $200 \mathrm{rpm}$ for $1 \mathrm{~h}$. The data were measured three times using the same sample and means. Vertical bars represent standard deviation.

$e e_{\mathrm{s}}$ showed the same tendency. The reaction reached equilibrium at a conversion near to $50 \%$, while $e e_{\mathrm{s}}$ was close to $100 \%$. It indicated that BCL had a good preference for (R)-1-phenylethanol, and all of (R)-1-phenylethanol had been nearly converted into $(R)$-phenylethyl acetate, while $(S)$-1-phenylethanol remained unchanged in the reaction solution. When the conversion and $e e_{\mathrm{s}}$ of the free lipase reached $50 \%$ and $99 \%$ at $30 \mathrm{~h}$, its enzyme activity was only $924.1 \mathrm{U} / \mathrm{min} / \mathrm{g}$ protein, while the corresponding $E$ value was more than 200. On the contrary, the immobilized BCL showed a very high initial reaction rate, the reaction equilibrium ( $e e_{\mathrm{s}}$ close to $99 \%$, conversion near to $50 \%$ ) could be achieved within $30 \mathrm{~min}$; the corresponding enzyme activity was $33,266.7 \mathrm{U} / \mathrm{min} / \mathrm{g}$

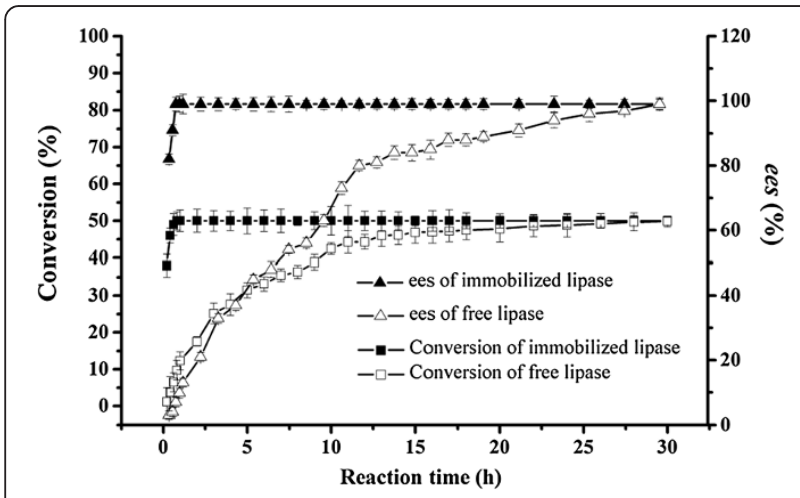

Figure 5 Effect of reaction time on conversion/ees of the free and immobilized BCL. Reaction condition: $0.1 \mathrm{~g} \mathrm{BCL}$ was added to $5 \mathrm{~mL} \mathrm{n}$-heptane containing $1 \mathrm{mmol}$ 1-phenylethanol, $4 \mathrm{mmol}$ vinyl acetate. The reactions were performed at $35^{\circ} \mathrm{C}, 200 \mathrm{rpm}$ for different reaction times. The data were measured three times using the same sample and means. Vertical bars represent standard deviation. protein. The enzyme activity of the immobilized BCL was 36 folds enhancement over the free lipase powder.

\section{Operational stability and reusability of the immobilized $\mathrm{BCL}$}

The reusability of the immobilized lipase is vital for cost-effective usage in the large-scale applications. In this study, the immobilized lipase can be easily separated from the reaction mixture by centrifugation. After every batch, the immobilized BCL was washed with nheptane to remove traces of substrate and products. Then, it was ready to be used for the next batch reaction under the same conditions. As shown in Figure 6, there was nearly no loss in enzyme activity and $e e_{\mathrm{s}}$ after the immobilized BCL had been continuously used for at least 30 cycles. Hence, it has been very clear that the immobilized lipase exhibited an excellent reusability. Therefore, the immobilized BCL is applicable not only to the batch reaction, but also to the continuous reaction and different reactor instruments.

\section{The BJH pore size distributions of MPR-NKA}

Compared with pure MPR-NKA, MPR-NKA adsorbed with lipase showed a decrease in the pore volume (from $0.985 \mathrm{~m}^{3} / \mathrm{g}$ to $0.881 \mathrm{~m}^{3} / \mathrm{g}$ ). As shown in Figure 7, MPRNKA contained relatively large pore volume, contributing to a better adsorption of lipase during immobilization. Compared with the pore volume of pure MPR-NKA, the decrease in the pore volume was attributed to the occupation of the enzyme in the pore channels, which indicated that BCL had been immobilized on MPR-NKA. It has been reported that the pore diameter should be at least four- to five-fold the protein diameter in order to prevent restrictions to the access of the enzyme [23]. Lipases are macromolecules of protein, with molecular weights about

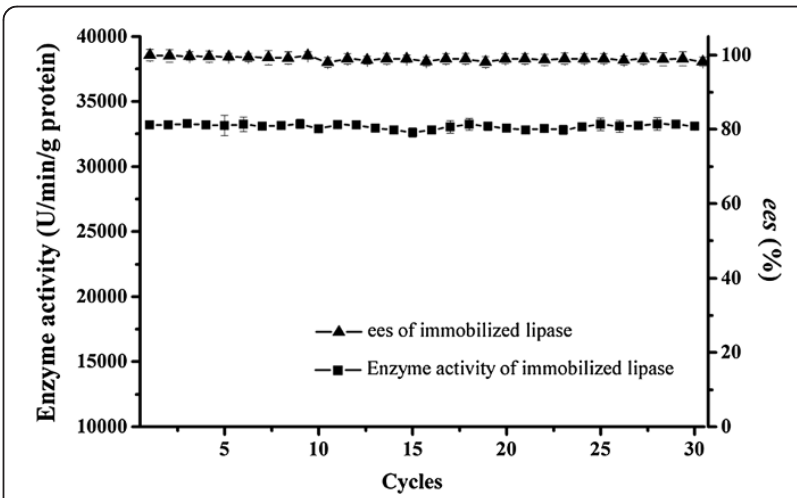

Figure 6 Reusability of the immobilized BCL. Reaction condition: $0.1 \mathrm{~g} \mathrm{BCL}$ was added to $5 \mathrm{~mL} \mathrm{n}$-heptane containing $1 \mathrm{mmol}$ 1phenylethanol, $4 \mathrm{mmol}$ vinyl acetate. The reactions were performed at $37^{\circ} \mathrm{C}, 200 \mathrm{rpm}$ for $1 \mathrm{~h}$. The data were measured three times using the same sample and means. Vertical bars represent standard deviation. 


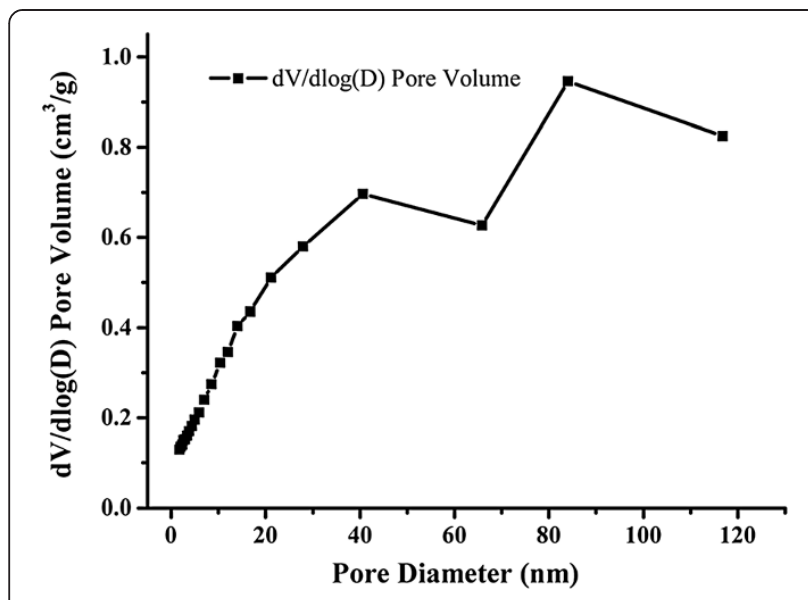

Figure $7 \mathrm{BJH}$ pore size distributions.

40,000-60,000 Da [24]. Moreover, the structure of Pseudomonas cepacia lipase has been resolved (rscb accession No. 1OIL) $[25,26]$. It was very easy to estimate the diameter of single BCL molecule (about $5 \mathrm{~nm}$ ), so the minimum pore diameter should be at least $20 \mathrm{~nm}$. As shown in Figure 7, the diameters of most pores were from 20 to $110 \mathrm{~nm}$, which matched the requirement of pore diameter.

\section{SEM and EDS analysis}

As shown in Figure 8, the detailed information about pore size distribution and shape of MPR-NKA has been given by SEM micrographs. Figure $8(\mathrm{a}, \mathrm{b})$ show the surface and internal surface of MPR-NKA, respectively. It can be seen that MPR-NKA has various pore volumes on its surface and inside, which also proves the conclusion from $\mathrm{BJH}$ pore size distribution. Figure 8(c) showed the pore volumes of MPR-NKA adsorbed with lipase, which indicates that $\mathrm{BCL}$ has been immobilized on MPR-NKA. This can also be confirmed by EDS analysis. The result of EDS (in Figure 9a) displays that $\mathrm{C}$ and $\mathrm{O}$ are present without other elements in pure MPR-NKA ( $\mathrm{H}$ element could not be detected in EDS). However, the elements of $\mathrm{C}, \mathrm{O}$ and $\mathrm{N}$ are present after $\mathrm{BCL}$ immobilized on MPR-NKA in Figure 9b, which also proves that the immobilization of BCL on MPR-NKA was successful [27].

Moreover, some researchers have reported that the inner surface may not be fully utilized for lipase adsorption even if the pore size is big enough during the immobilization process $[11,28]$. As shown in the Figure 8 $(a, b)$, the outer and internal surface of pure MPR-NKA were full of various pores before adsorption. After immobilization, surface of MPR-NKA was covered by lipase, and pores on the surface of MPR-NKA could not be found (in Figure 8c), which indicates that the lipase has almost been adsorbed by the MPR-NKA. It meant that the internal surface of MPR-NKA had been fully utilized, which was the possible reason for the high thermostability, organic solvent tolerance and operational stability of BCL immobilized on MPR-NKA.

\section{Secondary structure analysis of the free and immobilized BCL by FT-IR spectroscopy}

As known, protein has strong absorbance spectrum in the amide I region (1700-1600 $\mathrm{cm}^{-1}$ ) mainly due to the $\mathrm{C}=\mathrm{O}$ bending vibration [29]. The amide I band of proteins contains component bands that represent different secondary structure elements such as the $\alpha$-helix, $\beta$-sheet, $\beta$-turn and random coil. Their main absorbance spectra were: $\alpha$-helix: $1650-1658 \mathrm{~cm}^{-1}$, $\beta$-sheet: $1620-1640 \mathrm{~cm}^{-1}$, $\beta$-turn: $1670-1695 \mathrm{~cm}^{-1}$, and random coil: $1640-1650 \mathrm{~cm}^{-1}$, respectively [30]. FT-IR spectra of the pure MPR-NKA (Figure 10a); BCL immobilized MPR-NKA (Figure 10b) and free BCL (Figure 10c) were shown in Figure 10, respectively. Compared with spectra of pure MPR-NKA, BCL immobilized MPR-NKA had a characteristic peak at $1700-1600 \mathrm{~cm}^{-1}$, which could also be observed in the spectra of free BCL.

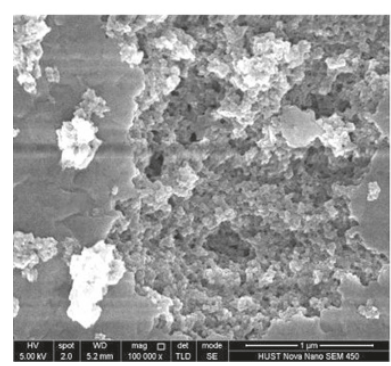

(a) Outer surface of MPR-NKA

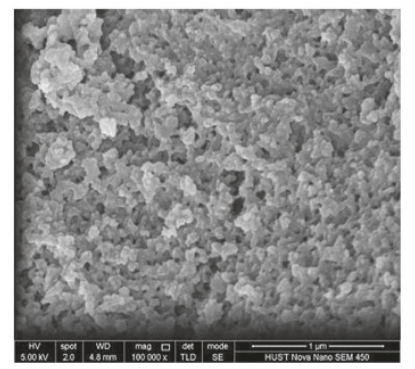

(b) Internal surface of MPR-NKA

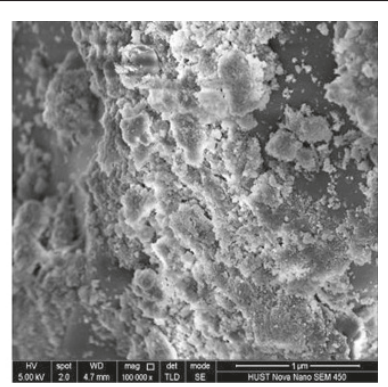

(c) MPR-NKA adsorbed with lipase

Figure 8 SEM images of the pure MPR-NKA and MPR-NKA immobilized BCL. (a) Outer surface of MPR-NKA (Magnification: 100 000, Accelerating Voltage: 5.00 kV); (b) Internal surface of MPR-NKA (Magnification: 100 000, Accelerating Voltage: 5.00 kV); (c) MPR-NKA adsorbed with lipase (Magnification: 100 000, AcceleratingVoltage: $5.00 \mathrm{kV}$ ). 


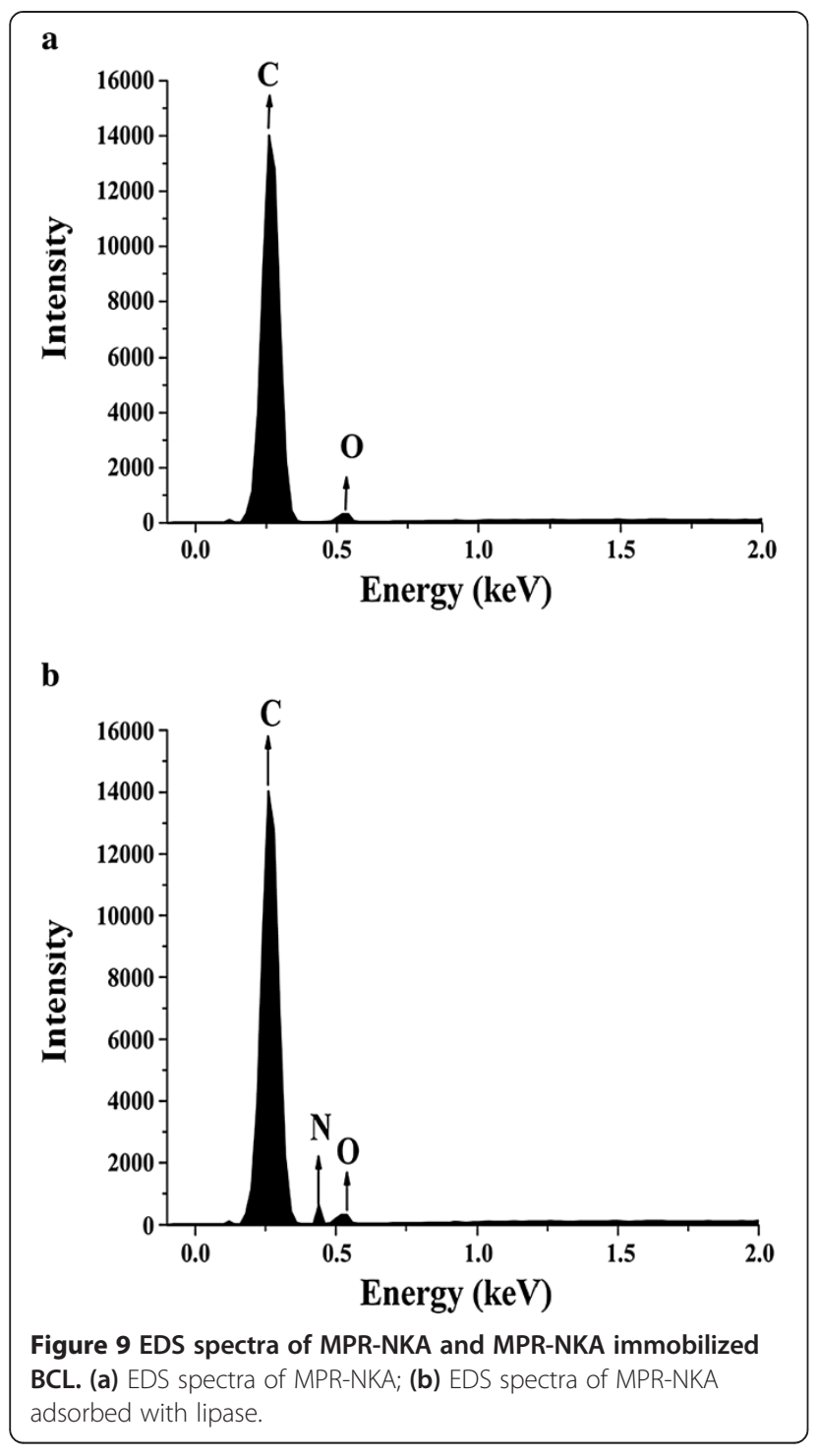

As shown in Table 2, the secondary structure element content of free lipase was: $\alpha$-helix: $28.3 \%, \beta$-sheet: $21.4 \%$, $\beta$-turn: $25.8 \%$, and random coil: $24.5 \%$, respectively. After immobilization, the immobilized BCL showed a decrease in $\alpha$-helix (11.8\%) and $\beta$-turn (15.9\%); an increase in $\beta$ sheet $(42.6 \%)$ and random coil (29.8\%). Foresti et al. reported that interfacial activation had been found when the lipase was adsorbed onto hydrophobic supports. The immobilized lipase was fixed in an open conformation and enhanced enzymatic activity was achieved [31]. Gao et al. pointed out that lipases are interfacial-active enzymes with lipophilic domains and can adopt both open and close conformations. The ionic microenvironment around lipase molecule, which was formed during immobilization procedure in buffer solution at a certain $\mathrm{pH}$ value, could be maintained as employed in organic solvent. This is socalled "pH memory effect", which helps to induce conformational changes of lipase resulting in the active form. Therefore, this would allow free access of the substrate to the active site of the immobilized lipase and increase activity of the immobilized lipase [12].

\section{Comparison with other immobilized lipases}

Compared with other immobilized lipases, the immobilized BCL exhibited a much higher catalytic efficiency. Chua et al. reported that immobilized lipase ChiroCLEC-PC (crosslinked enzyme crystals of Pseudomonas cepacia lipase) was used for the resolution of racemic 1-phenylethanol in organic solvents (including heptane) with different log $P$ values, while the maximal initial rate of reaction was $473.5 \pm 10 \mu \mathrm{mol} / \mathrm{min}$ and the reaction reached equilibrium conversion at $45 \%$ after 100 mins of reaction [18]. Compared with the cross-linked enzyme crystals method, the immobilized BCL showed a better catalytic efficiency (based on initial reaction rate and final conversion value). Wang et al. reported that lipase from B. cepacia was encapsulated inside zirconia particles by biomimetic mineralization of

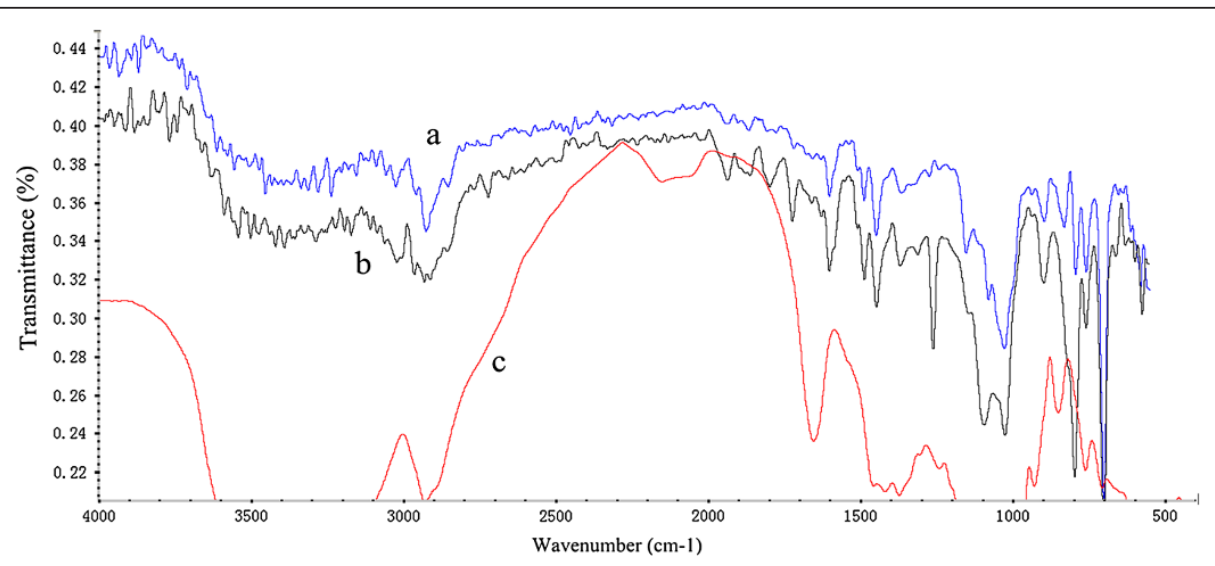

Figure 10 FT-IR spectra of (a: blue line) the pure MPR-NKA; (b: black line) MPR-NKA immobilized BCL and (c: red line) free BCL. 
Table 2 Quantitative estimation of the secondary structure elements of free and immobilized BCL

\begin{tabular}{lcccc}
\hline Solvent & $\boldsymbol{a}$ - Helix (\%) & $\boldsymbol{\beta}$ - Sheet (\%) & $\boldsymbol{\beta}$ - Turn (\%) & Random coil (\%) \\
\hline Free lipase & $28.3 \pm 1.09$ & $21.4 \pm 2.21$ & $25.8 \pm 0.91$ & $24.5 \pm 0.21$ \\
Immobilized lipase & $11.8 \pm 3.21$ & $42.6 \pm 1.21$ & $15.9 \pm 0.81$ & $29.8 \pm 0.71$ \\
\hline
\end{tabular}

$\mathrm{K}_{2} \mathrm{ZrF}_{6}$. After $48 \mathrm{~h}$ reaction under the optimal conditions, their immobilized lipase reached $49.9 \%$ with higher $e e_{\mathrm{s}}$ of $99.9 \%$, however, after 6 cycles, the conversion and $e e_{\mathrm{s}}$ were only $43 \%$ and $85 \%$, respectively [32]. Compared with the approach of encapsulating lipase within zirconia induced by protamine, our immobilized BCL exhibited a better reusability in the successive batch experiments.

In order to compare the catalytic efficiency between our immobilized BCL and several commercially available immobilized lipases usually used in literature, the $e e_{s}$ and conversions of Novozyme 435, Lipozyme RM IM, and Lipozyme TL IM were measured respectively. Under the same conditions of substrate molar ratios (vinyl acetate to racemic 1-phenylethanol) 4:1; reaction time $0.5 \mathrm{~h}$, reaction temperature $35^{\circ} \mathrm{C}, 0.1 \mathrm{~g}$ immobilized lipase and $5 \mathrm{~mL}$ solvent (heptane), their ee $e_{s}$ was $75 \%, 24 \%$ and $15 \%$, respectively. The corresponding conversions were $43.3 \%, 2.6 \%$ and $4.8 \%$, respectively. It can be seen that our immobilized BCL $\left(e e_{s}\right.$ 99\%; conversion 49\%) is much better than the commercially avaialable immobilized lipases in catalyzing enantioselective transesterification of 1-phenylethanol with vinyl acetate.

\section{Conclusion}

In this study, results were significantly enhanced in terms of enzyme activity and $e e_{\mathrm{s}}$ when BCL immobilized on MPR-NKA. Compared with the free BCL, the immobilized BCL had better thermostability and excellent reusability in non-aqueous medium. Combined strategies $\left(\mathrm{N}_{2}\right.$ adsorption-desorption, SEM and EDS) were used to characterize the immobilized lipase, which proved that MPR-NKA was an excellent support for lipase immobilization. FTIR analysis also indicated that improvement of enzyme activity and $e e_{\mathrm{s}}$ was closely correlated with the alteration of its secondary structure. Compared with the other immobilized lipases, the immobilized BCL exhibits a better catalytic efficiency, indicating a great potential for industrial applications.

\section{Methods}

\section{Materials}

Lipase from B. cepacia was purchased from Amano Enzyme Inc. (Nagoya, Japan). Racemic and optically pure 1phenylethanol was got from Alfa Aesar Co., Ltd (P. R. China). 1-Phenylethyl acetate; $(R)$ - and (S)-1-phenylethanol were bought from Sigma-Aldrich Co., Ltd (St. Louis, Missouri, USA). Novozym 435 (from Candida antarctica), Lipozyme RM IM (from Rhizomucor miehei) and Lipozyme TL IM (from Thermomyces lanuginose) were purchased from Sigma-Aldrich Co., Ltd (St. Louis, Missouri, USA). MPR was product of Tianjin Nankai Hecheng S \& T Co., Ltd (China). All organic solvents and other reagents were of analytical grade and were obtained commercially from Sinopharm Chemical Reagent Co., Ltd (Shanghai, China).

\section{Preparation of immobilized lipase}

The procedures of immobilization were described as follows: $1 \mathrm{~g}$ MPR and $5 \mathrm{~mL} \mathrm{99 \%} \mathrm{ethanol} \mathrm{was} \mathrm{added} \mathrm{into} \mathrm{a}$ $25 \mathrm{~mL}$ tube, then the mixture was put in $30^{\circ} \mathrm{C}$ shaking incubator at $200 \mathrm{rpm}$ for $2 \mathrm{~h}$ to wash out the residual catalyst and impurities. The ethanol was removed after MPR precipitated to the bottom of the tube. The residual MPR was washed with distilled water for three times. $5 \mathrm{~mL} 0.05 \mathrm{M}$ phosphate buffer $(\mathrm{pH} 7)$ was mixed with the residual MPR, the mixture was kept for $12 \mathrm{~h}$ at $30^{\circ} \mathrm{C}$. Then, the buffer was removed. After this pretreatment, MPR was kept in the tube. $0.8 \mathrm{~g}$ free BCL powder was dissolved in the $5 \mathrm{~mL} 0.05 \mathrm{M}$ phosphate buffer ( $\mathrm{pH} 7)$, this solution was loaded into the tube to mix with the MPR. The tube was stirred in a rotary shaker with a speed of $200 \mathrm{rpm}$ at $30^{\circ} \mathrm{C}$ for $2 \mathrm{~h}$. The suspension was separated after MPR precipitated to the bottom of the tube. The immobilized BCL (MPR adsorbing the lipase) was washed with $5 \mathrm{~mL} 0.05 \mathrm{M}$ phosphate buffer $(\mathrm{pH} 7)$ for three times to remove the unadsorbed lipase in the surface of the MPR, and then, protein content of the lipase solution and washed water was determined by the method of Bradford [33]. Five types of MPRs were used so as to choose the best immobilization support.

\section{Lipase activity and protein content measurements}

The enzyme activity was determined using 1-phenylethanol and vinyl acetate as substrate. One unit (U) of the enzyme activity was defined as the amount of the enzyme which produces $1 \mu \mathrm{mol} \alpha$-phenylethyl acetate per minute under the assay conditions. The reactions were performed in a $50 \mathrm{~mL}$ stoppered flask at $35^{\circ} \mathrm{C}$ and $200 \mathrm{rpm}$ for $1 \mathrm{~h}$. The assay conditions were used except when otherwise stated in the text. The protein content of free and immobilized BCL was $0.58 \mathrm{wt} \%$ and $0.50 \mathrm{wt} \%$, respectively. Immobilization efficiency (\%) was estimated as Eq. 1.

$$
\begin{aligned}
& \text { Immobilization efficiency }(\%) \\
& \quad=\frac{\text { immobilized protein }}{\text { total loading protein }} \times 100 \%
\end{aligned}
$$




\section{Reaction procedure}

Before usage, the organic solvent was dried over 4 A molecular sieves. Under the above mentioned conditions, reactions were carried out in $5 \mathrm{~mL}$ pure heptane, containing $1 \mathrm{mmol}$ racemic 1-phenylethanol, $4 \mathrm{mmol}$ vinyl acetate and $0.1 \mathrm{~g}$ free or immobilized BCL. The reaction mixture was put in a $50 \mathrm{~mL}$ stoppered flask at $35^{\circ} \mathrm{C}$ and $200 \mathrm{rpm}$ for $1 \mathrm{~h}$. These conditions were used except when the reaction parameters (molar ratio; temperature; reaction time) needed to be changed in the following text. The above experiments were all conducted in triplicate. After the reactions, the free or immobilized lipase was removed by centrifugation. Then, the samples were filtered through a $0.44 \mu \mathrm{m}$ filter and analyzed by HPLC.

\section{Analysis and calculation}

The samples were analyzed by HPLC (Model 2300-525 SSI. Co., Ltd USA) using a Chiralcel OD-H column (4.6 $\mathrm{mm} \times 250 \mathrm{~mm}$, Daicel Chemical, Japan). Samples $(5 \mu \mathrm{L})$ were eluted by a mixture of $\mathrm{n}$-hexane: 2 -propanol $(95: 5, \mathrm{v} / \mathrm{v})$ at a rate of $1.0 \mathrm{~mL} / \mathrm{min}$, and detected at a wavelength of $254 \mathrm{~nm}$ (Model 525 UV Detector SSI. Co., Ltd USA). The retention time of $(R)$ - and (S)-1-phenylethanol in the Chiralcel OD-H column was 7.28 and $8.23 \mathrm{~min}$, respectively.

According to method described by Chen et al. [34], enantioselectivity was expressed as $E$ value and calculated by Eq. $2, e e_{s}$ by Eq. 3, and $C$ by Eq. 4 .

$$
\begin{aligned}
& E=\frac{\ln [(1-C)(1-\text { ees })]}{\ln [(1-C)(1+\text { ees })]} \\
& e e s=\frac{S-R}{S+R} \\
& C=\frac{S 0+R 0-(S+R)}{S 0+R 0}
\end{aligned}
$$

where, $C$ represents the substrate conversion, $e e_{s}$ stands for the substrate enantiomeric excess, $S_{0}$ and $R_{0}$ respectively represent the concentrations of the $(S)$ - and $(R)$-enantiomers of 1-phenylethanol before reaction, $S$ and $R$ are the concentrations of the $(S)$ - and $(R)$-enantiomers of 1-phenylethanol after reaction.

\section{Characterization of the immobilization support with $\mathrm{N}_{2}$ adsorption-desorption}

The specific surface area, pore volumes, and average pore diameters were measured by nitrogen adsorption-desorption equipment (ASAP 2020 V4.00, Micromeritics Instrument Ltd, Shanghai). The specific areas of the MPR-NKA were calculated by the Brunauer-Emmett-Teller (BET) method, and the distributions of pore diameters were estimated by the desorption branches of the isotherms with the Barrett-Joyner-Halenda (BJH) model.

\section{Characterization of the immobilized BCL by SEM and EDS}

The immobilized BCL was analyzed with SEM and EDS (Nova Nano SEM 450, FEI Company, Eindhoven, Netherlands). The samples were coated with gold using a sputter coating system and measured at an acceleration voltage of $5 \mathrm{kV}$.

\section{FT-IR spectroscopy}

The samples were mixed with $\mathrm{KBr}$ and pressed into pellets. FT-IR measurements in the region of $400-4000 \mathrm{~cm}^{-1}$ were recorded at $25^{\circ} \mathrm{C}$ by Vextex 70 FT-IR spectrometer (Bruker, Germany) with the nitrogen-cooled, mercurycadmium - tellurium (MCT) detector. The spectrum acquisition (all samples were overlaid on a zinc selenide ATR accessory) is from IR spectra. The infrared spectrum of $\mathrm{KBr}$ has been subtracted from the infrared spectrum during each measurement. The conditions of the measurements were as follows: $20 \mathrm{kHz}$ scan speed, $4 \mathrm{~cm}^{-1}$ spectral resolution, 128 scan co-additions, and triangular apodization. The secondary structure element content was estimated by software PeakFit version 4.12 according to the method described by Yang et al. [35].

\section{Competing interests}

The authors declare that there are no competing interests.

\section{Authors' contributions}

$X \mathrm{~L}$ (i) designed the study, carried out the experiments and drafted the manuscript. SH contributed to the measurement of protein content and SEM. LX(U) revised the language. YY supervised the work and finalized the manuscript. All authors have read and approved the final manuscript.

\section{Acknowledgements}

The authors are deeply indebted to Muhammad Jawed Chanesra for his kind assistance in language editing. This work is financially supported by the

National Natural Science Foundation of China (Nos. 31070089, 31170078 and J1103514), the National High Technology Research and Development Program of China (2011AA02A204), the Innovation Foundation of Shenzhen Government (JCYJ20120831111657864), and the Innovation Foundation of HUST (2011TS100). Many thanks are indebted to Analytical and Testing Center of HUST for their valuable assistances in SEM, EDS and FT-IR measurement.

Received: 14 June 2013 Accepted: 23 October 2013

Published: 29 October 2013

\section{References}

1. Sellami M, Aissa I, Frikha F, Gargouri Y, Miled N: Immobilized Rhizopus oryzae lipase catalyzed synthesis of palm stearin and cetyl alcohol wax esters: Optimization by response surface methodology. BMC Biotechnol 2011, 11(1):68.

2. Alissandratos A, Baudendistel N, Flitsch S, Hauer B, Halling P: Lipasecatalysed acylation of starch and determination of the degree of substitution by methanolysis and GC. BMC Biotechnol 2010, 10(1):82.

3. Wang $H$, Sun $H$, Wei D: Discovery and characterization of a highly efficient enantioselective mandelonitrile hydrolase from Burkholderia cenocepacia $\mathrm{J} 2315$ by phylogeny-based enzymatic substrate specificity prediction. BMC Biotechnol 2013, 13(1):14. 
4. Liu Y, Chen D, Yan Y, Peng C, Xu L: Biodiesel synthesis and conformation of lipase from Burkholderia cepacia in room temperature ionic liquids and organic solvents. Bioresource Technol 2011, 102(22):10414-10418.

5. Liu T, Liu Y, Wang X, Li Q, Wang J, Yan Y: Improving catalytic performance of Burkholderia cepacia lipase immobilized on macroporous resin NKA. J Mol Catal B: Enzym 2011, 71(1-2):45-50.

6. Herbst D, Peper S, Niemeyer B: Enzyme catalysis in organic solvents: influence of water content, solvent composition and temperature on Candida rugosa lipase catalyzed transesterification. J Biotechnol 2012, 162(4):398-403.

7. Klibanov AM: Why are enzymes less active in organic solvents than in water? Trends Biotechnol 1997, 15(3):97-101.

8. Garcia-Galan C, Berenguer-Murcia Á, Fernandez-Lafuente R, Rodrigues RC: Potential of different enzyme immobilization strategies to improve enzyme performance. Adv Synth Catal 2011, 353(16):2885-2904.

9. Cao L: Immobilised enzymes: science or art? Curr Opin Chem Biol 2005, 9(2):217-226.

10. Alloue W, Destain J, Medjoub T, Ghalfi H, Kabran P, Thonart P: Comparison of Yarrowia lipolytica lipase immobilization yield of entrapment, adsorption, and covalent bond techniques. Appl Biochem Biotechnol 2008, 150(1):51-63.

11. Yan $Y$, Zhang $X$, Chen D: Enhanced catalysis of Yarrowia lipolytica lipase LIP2 immobilized on macroporous resin and its application in enrichment of polyunsaturated fatty acids. Bioresource Technol 2013, 131:179-187.

12. Gao Y, Tan T, Nie K, Wang F: Immobilization of lipase on macroporous resin and its application in synthesis of biodiesel in low aqueous media. Chin J Biotechnol 2006, 22(1):114-118.

13. Gao S, Wang Y, Diao X, Luo G, Dai Y: Effect of pore diameter and crosslinking method on the immobilization efficiency of Candida rugosa lipase in SBA-15. Bioresource Technol 2010, 101(11):3830-3837.

14. Kharrat N, Ali YB, Marzouk S, Gargouri Y, Karra-Châabouni M: Immobilization of Rhizopus oryzae lipase on silica aerogels by adsorption: Comparison with the free enzyme. Process Biochem 2011, 46(5):1083-1089.

15. Dib I, Nidetzky B: The stabilizing effects of immobilization in D-amino acid oxidase from Trigonopsis variabilis. BMC Biotechnol 2008, 8(1):72.

16. Shah S, Gupta MN: Kinetic resolution of ( \pm )-1-phenylethanol in [Bmim][PF6] using high activity preparations of lipases. Bioorg Med Chem Lett 2007, 17(4):921-924.

17. Ghanem A, Aboul-Enein HY: Application of lipases in kinetic resolution of racemates. Chirality 2005, 17(1):1-15.

18. Chua LS, Sarmidi MR: Immobilised lipase-catalysed resolution of (R, S)-1phenylethanol in recirculated packed bed reactor. J Mol Catal B: Enzym 2004, 28(2-3):111-119.

19. Ghamgui H, Karra-Chaâbouni M, Bezzine S, Miled N, Gargouri Y: Production of isoamyl acetate with immobilized Staphylococcus simulans lipase in a solvent-free system. Enzyme Microb Tech 2006, 38(6):788-794.

20. Persson M, Costes D, Wehtje E, Adlercreutz P: Effects of solvent, water activity and temperature on lipase and hydroxynitrile lyase enantioselectivity. Enzyme Microb Tech 2002, 30(7):916-923.

21. Xia X, Wang $C$, Yang $B$, Wang $Y$, Wang $X$ : Water activity dependence of lipases in non-aqueous biocatalysis. Appl Biochem Biotech 2009, 159(3):759-767.

22. Phillips RS: Temperature modulation of the stereochemistry of enzymatic catalysis: Prospects for exploitation. Trends Biotechnol 1996, 14(1):13-16.

23. Blanco RM, Terreros $P$, Muñoz N, Serra E: Ethanol improves lipase immobilization on a hydrophobic support. J Mol Catal B: Enzym 2007, 47(1-2):13-20

24. Gao S, Wang Y, Wang W, Luo G, Dai Y: Enhancing performance of lipase immobilized on methyl-modified silica aerogels at the adsorption and catalysis processes: Effect of cosolvents. J Mol Catal B: Enzym 2010, 62(3-4):218-224.

25. Ema T: Rational strategies for highly enantioselective lipase-catalyzed kinetic resolutions of very bulky chiral compounds: substrate design and high-temperature biocatalysis. Tetrahedron: Asymmetry 2004 15(18):2765-2770.

26. Schrag JD, Li Y, Cygler M, Lang D, Burgdorf T, Hecht H, Schmid R, Schomburg D, Rydel TJ, Oliver JD, et al: The open conformation of a Pseudomonas lipase. Structure 1997, 5(2):187-202.

27. Wang X, Zhou G, Zhang H, Du S, Xu Y, Wang C: Immobilization and catalytic activity of lipase on mesoporous silica prepared from biocompatible gelatin organic template. J Non-Cryst Solids 2011, 357(15):3027-3032

28. Chen B, Miller EM, Miller L, Maikner JJ, Gross RA: Effects of macroporous resin size on Candida antarctica lipase $B$ adsorption, fraction of active molecules, and catalytic activity for polyester synthesis. Langmuir 2006, 23(3):1381-1387.

29. Pribic R, Vanstokkum IHM, Chapman D, Haris PI, Bloemendal M: Protein secondary structure from Fourier transform infrared and/or circular dichroism spectra. Anal Biochem 1993, 214(2):366-378.

30. Haris PI, Severcan F: FTIR spectroscopic characterization of protein structure in aqueous and non-aqueous media. J Mol Catal B: Enzym 1999, 7(1-4):207-221.

31. Foresti ML, Alimenti GA, Ferreira ML: Interfacial activation and bioimprinting of Candida rugosa lipase immobilized on polypropylene: effect on the enzymatic activity in solvent-free ethyl oleate synthesis. Enzyme Microb Tech 2005, 36(2-3):338-349.

32. Wang J, Ma C, Bao Y, Xu P: Lipase entrapment in protamine-induced biozirconia particles: Characterization and application to the resolution of (R, S)-1-phenylethanol. Enzyme Microb Tech 2012, 51(1):40-46.

33. Bradford MM: A rapid and sensitive method for the quantitation of microgram quantities of protein utilizing the principle of protein-dye binding. Anal Biochem 1976, 72(1-2):248-254.

34. Chen CS, Fujimoto Y, Girdaukas G, Sih CJ: Quantitative analyses of biochemical kinetic resolutions of enantiomers. J Am Chem Soc 1982, 104:7294-7299.

35. Yang C, Wang F, Lan D, Whiteley C, Yang B, Wang Y: Effects of organic solvents on activity and conformation of recombinant Candida antarctica lipase A produced by Pichia pastoris. Process Biochem 2012. 47(3):533-537.

doi:10.1186/1472-6750-13-92

Cite this article as: Li et al.: Improving activity and enantioselectivity of lipase via immobilization on macroporous resin for resolution of racemic 1- phenylethanol in non-aqueous medium. BMC Biotechnology 2013 13:92.

\section{Submit your next manuscript to BioMed Central and take full advantage of:}

- Convenient online submission

- Thorough peer review

- No space constraints or color figure charges

- Immediate publication on acceptance

- Inclusion in PubMed, CAS, Scopus and Google Scholar

- Research which is freely available for redistribution 